\title{
Religion, Time Use, and Affective Well-Being
}

\author{
Chaeyoon Lim
}

\author{
University of Wisconsin-Madison
}

Abstract: This study examines whether religious people experience more positive affect and less negative affect in everyday life and, if they do, whether it is because of the differences in how they allocate time to different activities or because they feel differently during similar activities. Using the well-being module from the 2010-13 American Time Use Survey (ATUS), I show that churchgoers enjoy a significantly higher level of affective well-being on Sunday than non-churchgoers do. The supplementary analysis of the Gallup Daily Poll data suggests that this higher level of affective wellbeing among churchgoers is found throughout the rest of the week as well. Further analyses of the ATUS demonstrate that about 40 percent of the affective well-being gap between churchgoers and non-churchgoers on Sunday can be explained by how they spend their time differently. Churchgoers spend more time on Sunday participating in pleasant activities shared with family members and friends than non-churchgoers do. More than half of the gap, however, remains unexplained, implying that it has to do with how they feel during similar activities rather than the activities in which they participate. I discuss the implications of these findings on the mechanisms underlying the link between religion and subjective well-being.

Keywords: subjective well-being; religion; church attendance; time use

Citation: Lim, Chaeyoon. 2016. "Religion, Time Use, and Affective Well-Being." Sociological Science 3: 685-709.

Received: April 6, 2016

Accepted: May 8, 2016

Published: August 10, 2016

Editor(s): Jesper Sørensen, Kim Weeden

D0I: $10.15195 / \mathrm{v3} . \mathrm{a} 29$

Copyright: (C) 2016 The Author(s). This open-access article has been published under a Creative Commons Attribution License, which allows unrestricted use, distribution and reproduction, in any form, as long as the original author and source have been credited. (0)(1)
NE of the well-established findings in the sociology of religion as well as in the health research is the positive association between religious involvement and various aspects of subjective and psychological well-being (for review see Ellison and Levin 1998; Koenig, King, and Carson 2012). Numerous studies have linked religious beliefs and practices to higher levels of life satisfaction and happiness and to lower levels of psychological distress, anxiety, and depressive symptoms. Subjective well-being and other mental health outcomes are known to be strongly influenced by personal disposition and maybe by genetic factors (e.g., Diener and Lucas 1999; Lykken 1999). But a number of life circumstance factors, such as age, income, and marital status, have also been correlated with subjective and psychological well-being. Among such factors, religious involvement, especially attending religious services regularly, has been demonstrated to be one of the stronger correlates (e.g., Witter et al. 1985; Ellison et al. 1989)

This study aims to extend this literature on religion and subjective well-being by analyzing the American Time Use Survey data (ATUS) to explore the link between religious service attendance and affective well-being as experienced in daily life. Using this dataset, this study advances our understanding of the connection between religion and subjective well-being in several ways. First, because the ATUS uses the the Day Reconstruction Method (DRM) to measure positive and negative affect experienced during specific activities, it can capture the affective domain of subjective well-being more accurately (Kahneman and Krueger 2006; Csikszentmihalyi and Larson 2014; Reiss, Gable, and Maniaci 2014). Conventional survey 
measures of affective well-being typically ask respondents to assess their general affective experiences, often over a relatively long period of time. As a result, these measures are confounded by respondent's overall level of evaluative well-being and also susceptible to the biases due to retrospective evaluation and aggregation (e.g., Diener et al. 2010). By using the data collected with the DRM, which measures positive and negative affective experiences associated with specific activities, this study offers a cleaner test of the connection between religious participation and the affective domain of subjective well-being compared to previous studies.

In addition to offering more robust empirical foundations, this study advances our understanding of how and why churchgoers and non-churchgoers differ in their affective experiences in everyday life. I ask how much of the difference in the affective well-being between churchgoers and non-churchgoers can be attributed to how they spend their time on different activities as opposed to how they experience same or similar activities. In other words, do churchgoers and non-churchgoers differ in their affective well-being because of what they actually do in everyday life or because of how they feel while participating in the same activities? By probing how the differences in time use are related to the variation in affective well-being, this study throws light on one of the long-standing questions in the literature; that is, which aspects of religion are critical in the link between religious involvement and subjective well-being, and how?

I draw from the literature on subjective and psychological well-being to develop hypotheses about the relationship between religious service attendance and daily affective experiences. I test them using the 2010-13 American Time Use Survey, which contains information on the positive and negative affect respondents experience during specific activities they report in a time diary. The findings highlight the importance of religion both as a social institution that serves as a focal point around which people coordinate social life and as a source of social and psychological resources that protect people from stressful daily events and help them manage their emotions. As a result, this study expands and deepens our understanding of how religious participation is linked to quality of life and subjective well-being. This study also demonstrates how time-use data can be used to systematically examine the distribution of daily affective experiences by key sociodemographic factors and social contexts.

\section{Religious Service Attendance and Affective Well-Being}

Numerous studies from the United States and abroad have documented that people who are religiously involved rate their life satisfaction and happiness higher in surveys than those who are not (e.g., Ellison 1991; Krause and Wulff 2005). Studies have also shown that religious individuals enjoy a higher level of psychological well-being and mental health than non-religious people do (McCullough and Larson 1999; Ellison and Fan 2008; Ellison et al. 2009; Sternthal et al. 2010). Although there is a growing body of literature on the potentially negative impacts of religion on physical and mental health outcomes, especially among people who experience "religious doubts" or "spiritual struggle" (Krause and Ellison 2009; Ellison and Lee 2010), a large majority of the studies, at least in the United States, support 
the positive association between religious involvement and various measures of well-being.

This study extends this literature by focusing on the affective domain of subjective well-being, especially positive and negative affect as experienced in everyday life. Given the well-established findings on the link between religious involvement and various mental health outcomes, it may seem obvious that religious individuals would also have more positive affective experiences in daily life. However, previous studies have mostly focused on affective well-being as a stable state for a period of time or certain pathological states rather than pleasant and unpleasant experiences in everyday life (Thoits 1989). They have relied on survey measures that ask respondents to provide an overall assessment of their emotional states, which can be influenced by their general levels of happiness and personal dispositions and also prone to retrospective and aggregation bias (Kahneman and Krueger 2006; Diener et al. 2010). In order to measure daily affective experiences properly, Kahneman and Krueger (2006:9) argue that one needs to avoid "effects of judgment and of memory as much as possible." Conventional survey measures are also vulnerable to individual differences in the use of response scale. In short, we still need more direct and robust empirical investigations of the relationship between religion and the affective domain of subjective well-being with better measures of daily affective experiences.

Unlike the cognitive or evaluative domain of subjective well-being, religion's relationship with daily affective experiences can also be less intuitive; thus, why and how attending religious services is positively related to affective well-being needs to be better understood. Although an individual's mood at any given moment can be dependent on their personality traits and general life circumstances, it is also shaped by the situations people find themselves in at the moment (Diener and Lucas 1999). Even people who are highly satisfied with their lives in general experience considerable fluctuations in affective well-being from moment to moment. Naturally, individuals who allocate more time to pleasant activities and less time to unpleasant ones would experience a higher level of affective well-being (Kahneman et al. 2010). Determining which activities are pleasant is a matter of personal taste, but studies have found that there are certain activities during which people generally feel more or less pleasant (Robinson and Godbey 1999; Krueger et al. 2009). In particular, studies suggest that whether people spend enough time with family or friends is one of the strongest predictors of affective well-being and happiness in general (e.g., Cohen 2004; Waldinger and Schulz 2010). Kahneman (2011:395) goes as far as to say that happiness is, in effect, "the experience of spending time with people you love and who love you".

Sociological research on emotion also suggests a close connection between social interactions and positive affective experiences (Thoits 1989; Baumeister and Leary 1995; Reiss 2001; Turner and Stets 2006). Collins (2004) theorizes that both positive and negative emotional energies result from "interaction rituals." He argues that a successive interaction ritual generates positive emotional energies among its participants, lifting their spirits and creating social solidarity among them. As a result, emotional energy is largely a function of social density-the proportion of time during which individuals engage in social interactions with other people. 
In short, a number of theories predict that people would experience more positive affect during their intimate interactions with others. People who attend religious services regularly may experience a higher level of affective well-being because they spend more time socially with family members and friends. This would be particularly the case on Sunday in the United States when most Christian traditions hold their major worship services. Worship service itself is a social activity during which participants share collective rituals that can generate positive emotional energies (Collins 2004). In addition, people may also participate in additional social activities before or after worship service, such as a supper with fellow congregants or volunteering for church-related activities- the kinds of activities people tend to find pleasant.

In principle, non-churchgoers can spend their Sunday in an equally social manner by organizing events with family or friends and participating in non-religious organizational activities. However, organizing social activities is constrained by scheduling conflicts and requires coordination efforts (Winship 2009). The weekend is a socially "coordinated time off" that makes it easy to schedule social activities (Young and Lim 2014), but organizing a social event, especially with people outside one's household, still demands efforts to find a time, a place, and a focal activity. Worship service on Sunday, in a sense, is an institutionalized social time that does not require such efforts. Worship service can also serve as a natural focal point to plan additional social events. As a result, I predict that on Sunday, people who attend religious services will spend more time socially with family and friends and thus will experience more positive affect than people who do not attend services.

- H1a: Churchgoers will spend more time socially with family and friends on Sunday because of the time they spend in religious services and the additional social time before and after.

- H1b: The difference in affective well-being on Sunday between churchgoers and non-churchgoers will be partly explained by the amount of social time they spend with family and friends.

In addition to spending more time socially on Sunday, churchgoers may draw more intense pleasure from their social time than non-religious individuals (McFadden and Levin 1996). Friends who share a religious faith and social interactions with them in a place of worship may be different qualitatively and contribute more to subjective well-being than social interactions in other contexts (Lim and Putnam 2010). Similarly, social time organized around worship services may generate more intense positive emotions than other social activities do. Religious individuals may also enjoy social activities more than non-religious individuals because of their personal dispositions. Psychological studies have shown that people with certain personality traits (especially extraversion) have a higher sensitivity to social stimuli and thus draw more pleasure from a similar social experience than those who lack such traits do (Diener and Lucas 1999). Religious individuals may be more likely to possess such personality traits and, as a result, they may experience more positive affect during social activities. Either way, I expect that religious individuals experi- 
ence a higher level of affective well-being compared to non-religious individuals, particularly during social activities than during non-social activities.

- H2: Churchgoers will report a higher level of affective well-being compared to non-churchgoers, particularly during the activities shared with family and friends than during non-social activities.

Although many of the activities that people find pleasant are social, there are non-social activities that people enjoy as well. In addition, certain social activities (e.g., dining at a good restaurant with friends) can be more pleasant than others (e.g., grocery shopping with family members). Another possibility, therefore, is that churchgoers simply spend more time on Sunday on pleasant activities in general than non-churchgoers do, whether they are social or not, and, as a result, they experience a higher level of affective well-being than non-churchgoers do.

- H3a. Churchgoers will spend more time on Sunday participating in the activities (both social and non-social) that people in general find pleasant than non-churchgoers do.

- H3b. The difference in affective well-being between churchgoers and nonchurchgoers will be explained by the amount of time they spend on pleasant activities.

The hypotheses so far posit that churchgoers experience a higher level of affective well-being than non-churchgoers because they actually allocate more time for the kinds of activities that are pleasant, including social activities shared with family and friends. In addition, they may derive more positive affect from similar social activities, either because social activities shared with others of the same faith generate stronger positive affect than other social activities or because they have personal dispositions that help them enjoy social activities more.

Alternatively, however, religious individuals may enjoy a higher level of affective well-being not necessarily because of what they do, but because of how they feel during the same activities. In other words, religious and non-religious individuals may not differ much in how they spend time; instead, they may experience different feelings during similar activities. The research on religion and well-being has long stressed religion's role as a coping mechanism. A number of studies have suggested that religion can provide emotional comfort and an interpretational framework to help people coping with life events, especially challenging or stressful ones (Kirkpatrick 1995; Pargament 1997; Ellison and Levin 1998). Thanks to religion's role as social and psychological resources for coping, religious individuals may experience a higher level of affective well-being than non-religious people regardless of activities they participate in. In fact, we may expect that religious individuals may prove to be more resilient emotionally than non-religious people and thus display more positive attitudes during mundane activities or challenging daily events that people usually find unpleasant or stressful. This reasoning leads 
to a hypothesis that competes against the earlier hypotheses, especially $\mathrm{H} 2$.

- H4: Churchgoers will report a higher level of affective well-being than nonchurchgoers regardless of the activities they participate in on Sunday.

\section{Data and Measurement}

To explore the relationship between religious involvement and affective well-being, I use the Well-Being Supplement in the American Time Use Survey. In 2010, the ATUS used the Day Reconstruction Method to collect information on affective states of respondents during different types of activities they reported in a time diary (Bureau of Labor Statistics 2011). After the respondents completed their time diary, the ATUS randomly selected three activities for each respondent and asked respondents about their affective states during each activity with respect to the following six dimensions: "happy," "meaningful," "tired," "stressed," "sad," and "pain."1 For each dimension, respondents rated their affective states on a scale from zero to six, zero indicating that they did not experience the feeling at all and six indicating that the feeling was very strong during the activity. The Well-Being Supplement was repeated in 2011 and again in 2013. I pool all three years to construct the analytic dataset.

The ATUS respondents fill out a time diary for only one day of the week. Half of the respondents complete the diary for one day on the weekend and the other half for one weekday. In this study, I focus on the respondents who complete the diary on Sunday. Participation in religious activities, the key explanatory variable of the study, is mostly reported on Sunday, and thus it is the only day of the week when I can systematically compare people who participate in religious activities with those who do not. Less than 1.5 percent of the respondents typically report attending worship service in weekdays and only 3.7 percent on Saturday, making it difficult to effectively compare them with non-participants in those days.

Because my analysis is limited to the Sunday data, however, any finding about the difference in affective well-being between religious and non-religious individuals may not be generalizable to the rest of the week. Sunday is a special day for religious people, especially those in Christian traditions, and thus it is plausible that they experience a particularly high level of affective well-being on the day. Also we cannot learn much about affective well-being among people in other religious traditions (especially non-Christian ones) that hold worship services in other days of week or do not require regularly attending worship services.

These are serious limitations, but Sunday is when most people do not need to work and thus have freedom to choose how to allocate their time. It is also when people have the fewest "scheduling constraints" and therefore can coordinate social activities with their family and friends (Winship 2009). As such, Sunday is the day people can allocate their time in order to maximize their utility and thus an ideal day to study the relationship between time use and affective well-being. In addition, I conduct supplementary analyses using the Gallup Daily Poll to explore the relationship between religious involvement and affective well-being on weekdays and Saturday. The Gallup Daily Poll have interviewed about 1,000 American 
adults since 2008 on a daily basis (for more information see Gallup, Inc. 2009). The pooled sample between 2008 and 2013 that I use in this study has a sample size of over 1.3 million people, including large numbers of respondents from various religious backgrounds. In the Gallup data, I focus on a set of questions concerning pleasant and unpleasant feelings, such as happiness, enjoyment, worry, and stress, that respondents experienced yesterday. These questions ask respondents about their affective experiences during the course of a whole day rather than during a specific activity, making the data less than ideal and not directly comparable to the ATUS well-being data. Still, analyzing the Gallup data will offer some useful insights on daily affective experiences during weekdays and Saturday.

\section{Dependent Variable}

Using the ATUS Well-Being Supplement, I create a "pleasantness index" or the "Pindex" (Krueger et al. 2009). For each activity sampled for the well-being module, I compare the scores on all five questions on feelings and code it as zero if the highest-rated affect is negative (i.e., tired, stressed, sad, or pain) and one if it is positive (i.e., happy). In the case of tie, I code the index as zero (i.e., negative). I exclude the "meaningful" question from the index because its affective valence is not as clear as other emotions. As a robustness check, I repeated all analyses presented in the paper with an alternative index that includes the "meaningful" question. The results, which are available in the online supplement, are similar to those that are presented in the paper.

The resulting P-index summarizes a net affective state associated with each activity, zero being negative and one positive. I also create the P-index for each individual respondent by weighing the index with the duration of each activity and summing it over the three randomly sampled activities. To distinguish this from the activity-level P-index, I refer to the former as $\mathrm{P}_{i}$-index (individual-level) and the latter as $\mathrm{P}_{a}$-index (activity-level) in the rest of the paper. The $\mathrm{P}_{i}$-index ranges from 0 to 1 and can be interpreted as the time during which the highest-rated affect is positive as a proportion of the total time spent for the three randomly sampled activities. The average $\mathrm{P}_{i}$-index on Sunday is 0.67 , meaning that, on average, respondents spend 67 percent of the time in a positive mood. In comparison, the $\mathrm{P}_{i}$-index is 0.67 on Saturday and 0.60 during weekdays.

Compared to conventional survey measures of subjective well-being, the Pindex based on the DRM has some important merits. First, because it is based on contemporaneous, momentary reports on affective states associated with specific activities, the P-index can minimize the biases due to retrospective evaluation and aggregation (Reiss et al. 2014). Because the P-index focuses on the relative ranking of positive and negative affect associated with each activity, as Krueger et al. (2009) suggest, it may also be less susceptible to different usages of a scale by individual respondents and thus less vulnerable to the problem of interpersonal comparability than conventional survey measures. Finally, because the ATUS measures affective experiences associated with specific activities people participate in, I can examine how much of the observed variations in affective well-being is due to what they do as opposed to how they feel during the same activities. 
Because it condenses five ordinal questions into a binary variable, however, P-index throws away lots of information. To ensure that the findings based on this measure are robust and not obscuring some important patterns, I repeated all the key analyses using a more nuanced measure of affective balance that is the difference between the highest rated positive and negative affect items. The results, which are available in the online supplement, are similar to those based on the P-index.

In the Gallup data, the key dependent variable is a measure of affective wellbeing created from the questions that ask whether respondents experienced the following "a lot of the day yesterday": smile or laugh, enjoyment, happiness, worry, sadness, stress, and anger. The response to each of these questions is binary. I summarize these questions into a composite variable that measures daily affective balance by subtracting the mean of the four negative affect questions from the mean of the three positive ones and then standardizing it so that the mean of the variable is zero with standard deviation of one (Diener et al. 2010).

\section{Explanatory Variable}

Religious involvement. The key explanatory variable of the study is respondent's participation in religious activities. Unfortunately, the ATUS does not ask about respondent's general religious involvement. Instead, I use the religious activities reported in the time diary to identify respondents who are religiously involved. About 22 percent of the Sunday respondents in the 2010-13 ATUS report attending religious services as one of the activities they participate in. I code all respondents who attend religious services on Sunday as "churchgoer" and the rest as "nonchurchgoer." A small number of respondents (2.7 percent) do not attend religious services but participate in other religious or spiritual activities, such as reading the scriptures, meditating, or praying alone. I group them with non-churchgoers, but how these respondents are grouped has little influence on the findings.

This measure of religious involvement does not capture the intensity of religious involvement because it is based on a time diary from a single day and thus treats regular churchgoers and occasional churchgoers as equally observant as long as they happen to be in church on the day they complete the time diary. Because the ATUS does not provide any measure of religious denomination or beliefs, I cannot test how different aspects of religiosity, other than religious service attendance, influence an individual's affective well-being, nor can I examine how the link between religious involvement and affective well-being varies across denominations, especially in religions that do not hold worship services on Sunday.

However, previous studies have found that the frequency of religious service attendance is the strongest and the most consistent predictor of various measures of subjective well-being (e.g., Witter et al. 1985; Lim and Putnam 2010), making it pertinent to focus on this specific aspect of religious participation. In addition, although it is still possible that religious individuals over-report their religious activities on Sunday in retrospective time diary, a number of studies have suggested that the time diary-based measure of church attendance can be less susceptible to social desirability bias compared to conventional survey measures (Hadaway, 
Marler, and Chaves 1993; Presser and Stinson 1998; Brenner 2011). In the 2012 General Social Survey, for example, more than 26 percent of the respondents claim that they attend religious services every week or more frequently, and another 13 percent say that they attend nearly every week or at least two or three times a month. In comparison, only about 22 percent of the ATUS respondents on Sunday report that they attended religious worship services, indicating that the social desirability bias is probably less severe in time diary than in conventional surveys. Finally, most of the aforementioned limitations of the time diary measure of attendance are likely to lead to the underestimation of the differences between churchgoers and non-churchgoers in affective well-being and thus provide a more stringent test for the hypotheses.

In the Gallup data, religious involvement is measured with the following question about the frequency of religious service attendance: "How often do you attend church, synagogue, or mosque-at least once a week, almost every week, about once a month, seldom, or never?"

Social time. To examine whether the amount of time spent on social activities is responsible for the differences in affective well-being between religious and non-religious individuals, I compare the amounts of different types of social time respondents report in their time diary on Sunday. For each activity reported, the ATUS asks who else was present in the room or accompanied during the activity. ${ }^{2}$ Even though being in the same room does not necessarily mean that respondents were actively interacting with them or engaged in a joint activity, this question can provide a reasonable estimate of social time in each day. Because the emotional rewards of social time can vary by the types of relationships between respondents and people who are present, I examine the following types of social time separately: a) time spent only with household members; b) time spent with non-household family members, relatives, and friends (with or without household members present); and c) time with work-related ties (e.g., boss, coworkers, customers, etc.). If nobody was present during an activity, I count the time spent for the activity as "non-social time." On average, the 2010-2013 ATUS respondents spent about 290 minutes alone on Sunday, compared to 300 minutes on Saturday and 349 minutes during weekdays.

Other individual-level covariates. I adjust for a number of individual-level covariates for all regression analyses presented in the paper. They include basic demographic factors such as age, sex, and race. Respondent's age is included as a continuous variable. I experimented with the quadratic term, but there was little sign of non-linear relationship between age and the P-index. Race is measured in five categories: non-Hispanic White, non-Hispanic Black, Hispanic, Asian, and others. I also adjust for respondent's marital status in three categories (married or partnered, widowed/divorced/separated, and never married) and whether or not respondents have children under 18.

With respect to respondent's socioeconomic status, I control for educational achievement (less than high school, high school degree, some college, college degree, and postgraduate education), labor market status (employed, unemployed, retired, disabled, and others), and logged household income. Among these, labor market status is the only variable that is consistently related to the P-index, as retirees report a higher level of well-being and the disabled a lower level than the employed. 
Finally, I adjust for self-reported general health because unhealthy individuals are less likely to attend worship services and experience more negative affect, especially feeling more pain and fatigue. Descriptive information of these variables can be found in the online supplement.

\section{Analytical Approach}

The ATUS data has a multi-level structure as activities are nested in each individual respondent. I conduct analyses both at the individual respondent level and the activity level. For the individual-level analysis, I aggregate the activity-level data for each respondent and model the $\mathrm{P}_{i}$-index as a function of individual-level characteristics, including religious service attendance. To examine whether religious and non-religious individuals differ in how they allocate their time on Sunday, I also compare the amounts of social time and the time they spend for different activities.

For the activity-level analysis, I employ multilevel regression analysis so that I can consider both activity- and individual-level covariates. The dependent variable ( $\mathrm{P}_{a}$-index) in this approach is binary: one if the highest-rated affect is positive and zero otherwise. The key activity-level covariates include the types of people who are present during a given activity and the average $\mathrm{P}_{a}$-index for the activity among all respondents who reported about their feelings during the activity. I use these variables to examine how much of the difference in affective well-being between churchgoers and non-churchgoers can be attributed to the allocation of time among different activities with varying levels of affective rewards.

In the ATUS data, churchgoers are substantially less likely to report any paid work on Sunday than non-churchgoers do, even after adjusting for demographic factors. Although this may reflect the differences in their preferences, some Sunday workers may have no choice but to work and thus experience an unusually low level of affective well-being. In addition, some religious individuals may be particularly unhappy when they cannot attend religious services because they have to work on Sunday. In the ATUS data, such individuals would be classified as non-churchgoers, potentially downwardly biasing the estimate of affective well-being among nonchurchgoers. To address these concerns, I repeat the key analyses only with the respondents who report no paid work or work-related activities (e.g., commuting) on Sunday.

\section{Findings}

I begin with individual-level analyses that compare the $\mathrm{P}_{i}$-index between people who attend religious services on Sunday and those who do not. I estimate an OLS regression model that predicts the $\mathrm{P}_{i}$-index with religious service attendance and all other individual-level covariates. Using this model, I compute the predicted values of the $\mathrm{P}_{i}$-index for churchgoers and non-churchgoers. The predicted $\mathrm{P}_{i}$-index scores and their 95 percent confidence intervals are shown in Figure 1. The full regression results are available in the online supplement. 


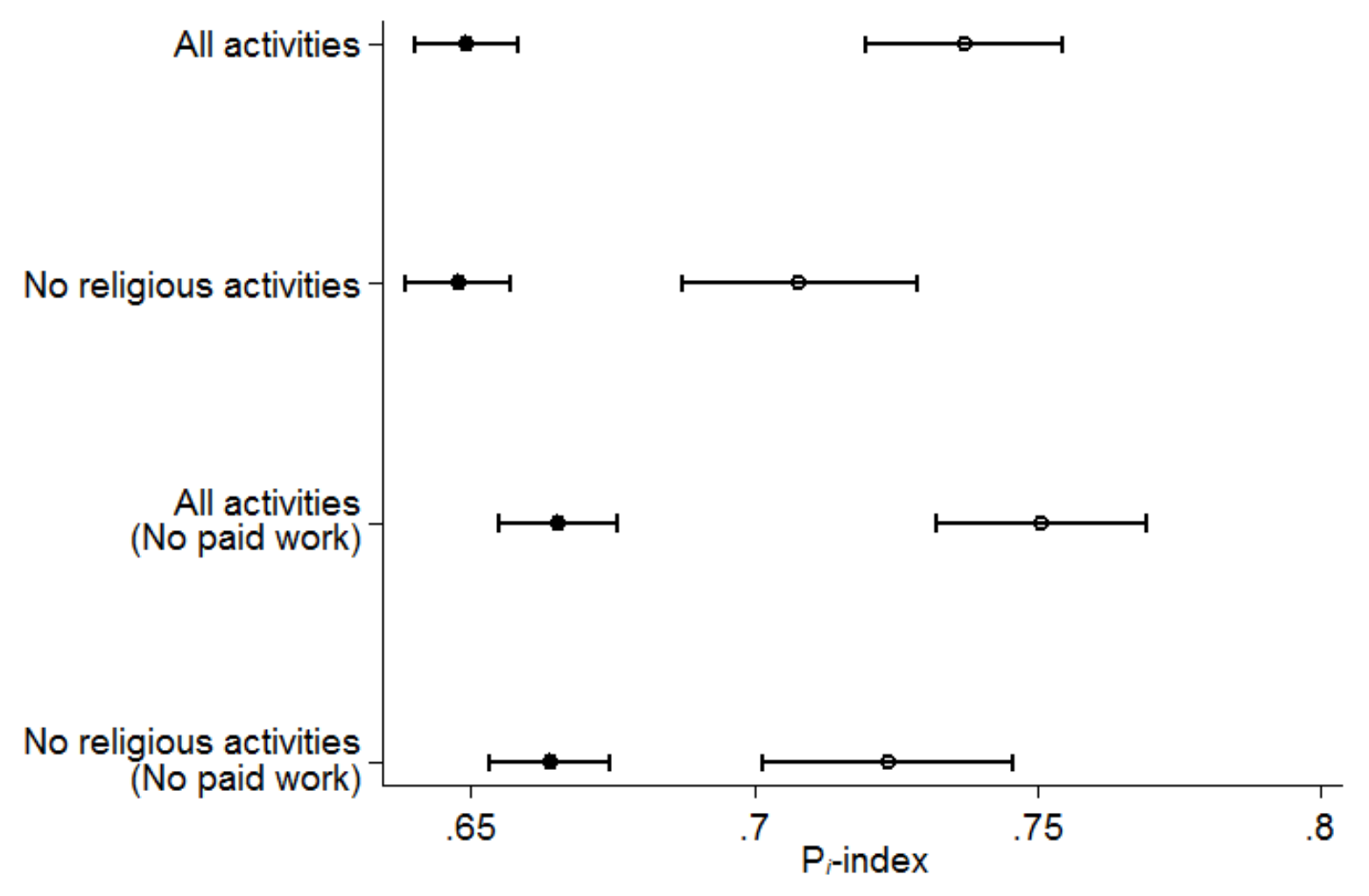

- Non-churchgoer o Churchgoer

Figure 1: Predicted $\mathrm{P}_{i}$-index for churchgoers and non-churchgoers. The predicted $\mathrm{P}_{i}$-indices and their 95 percent confidence intervals were computed from the OLS regressions that adjust for all individual covariates discussed in the paper. The lower half of the figure shows the results from the analyses that are restricted to the respondents who do not report any paid work-related activity on Sunday. The full regression results can be found in the online supplement.

Figure 1 shows that churchgoers have a higher $\mathrm{P}_{i}$-index score than non-churchgoers, meaning that they spend a larger proportion of their Sunday in a positive mood. Churchgoers spend about 74 percent of their time on Sunday (i.e., of the total time spent for the three randomly sampled activities) in a net positive affective state. In comparison, non-churchgoers spend 65 percent of their time in a net positive state. This gap is larger than the difference in the average $\mathrm{P}_{i}$-index between weekend and weekdays. In fact, religious service attendance is one of the strongest predictors in the model, only next to general health and disability.

To ensure that the observed differences are not driven entirely by positive feelings that churchgoers experience during worship services or other religious activities, Figure 1 also shows the predicted $\mathrm{P}_{i}$-index of churchgoers after excluding religious activities ("No religious activities"). Without religious activities, the gap between churchgoers and non-churchgoers shrinks but remains substantial. In short, 
churchgoers spend a larger proportion of Sunday in a positive mood than nonchurchgoers do, even without counting the time they spend on religious activities. The lower part of Figure 1 suggests that the patterns remain similar when I restrict the analyses to the respondents with no paid work activity on Sunday.

To test H1a, which predicts that churchgoers would spend more time socially with family and friends than non-churchgoers do, Figure 2 compares the amounts of social time they spend with different kinds of people on Sunday. These are the predicted minutes that adjust for all individual-level covariates. I use negative binomial regression because social time is a count variable and there is a strong sign of over-dispersion. Again, the full regression results can be found in the online supplement.

As Figure 2 reveals, churchgoers and non-churchgoers spend a similar amount of time with the members of their households-typically their spouse, partner, and children-on Sunday. However, they diverge significantly when it comes to the amount of time they spend with non-household family members and friends. ${ }^{3}$ On average, churchgoers spend about 65 minutes more with non-household family members and friends than non-churchgoers do. When we exclude religious activities, however, the gap largely disappears: churchgoers spend 177 minutes with non-household family members and friends, whereas non-churchgoers spend 172 minutes with such people. The additional time churchgoers spend with family members and friends on Sunday, in other words, is mostly attributable to the time they spend on religious activities. Non-churchgoers do not substitute churchgoer's time for religious activities with other social activities shared with family members or friends. Instead, non-churchgoers spend about 70 minutes more alone and 35 minutes more with work-related ties than non-churchgoers do. When the analyses are restricted to the respondents with no paid work activity, the difference in non-social time remains unchanged, but the gap in the amount of time spent with work-related ties largely disappears (the full results available in the online supplement).

To what extent do these differences in social time explain the gap in affective well-being between churchgoers and non-churchgoers? To answer this question, I turn to the activity-level analysis to examine whether people indeed experience a higher level of affective well-being during social activities and whether adjusting for social time reduces the affective well-being gap between churchgoers and non-churchgoers ( $\mathrm{H} 1 \mathrm{~b})$. Because the $\mathrm{P}_{a}$-index is binary, I use multi-level logistic regression. Table 1 shows the results concerning the key variables of interest. The full results that include all control variables are available in the online supplement.

I first estimate a baseline model (model 1 in Table 1) that includes religious service attendance and all other individual-level covariates. Consistent with the findings at the individual level, model 1 shows that churchgoers have a significantly higher $\mathrm{P}_{a}$-index than non-churchgoers do, which indicates their higher probability to have the positive affect rank higher than the negative affect during a given activity. The predicted $\mathrm{P}_{a}$-index for churchgoers is 0.73 compared to 0.65 among non-churchgoers, mirroring the difference observed in Figure 1.

In model 2, I add a set of dummy variables for the types of relationships between respondents and people who are present during a given activity. The omitted cate- 


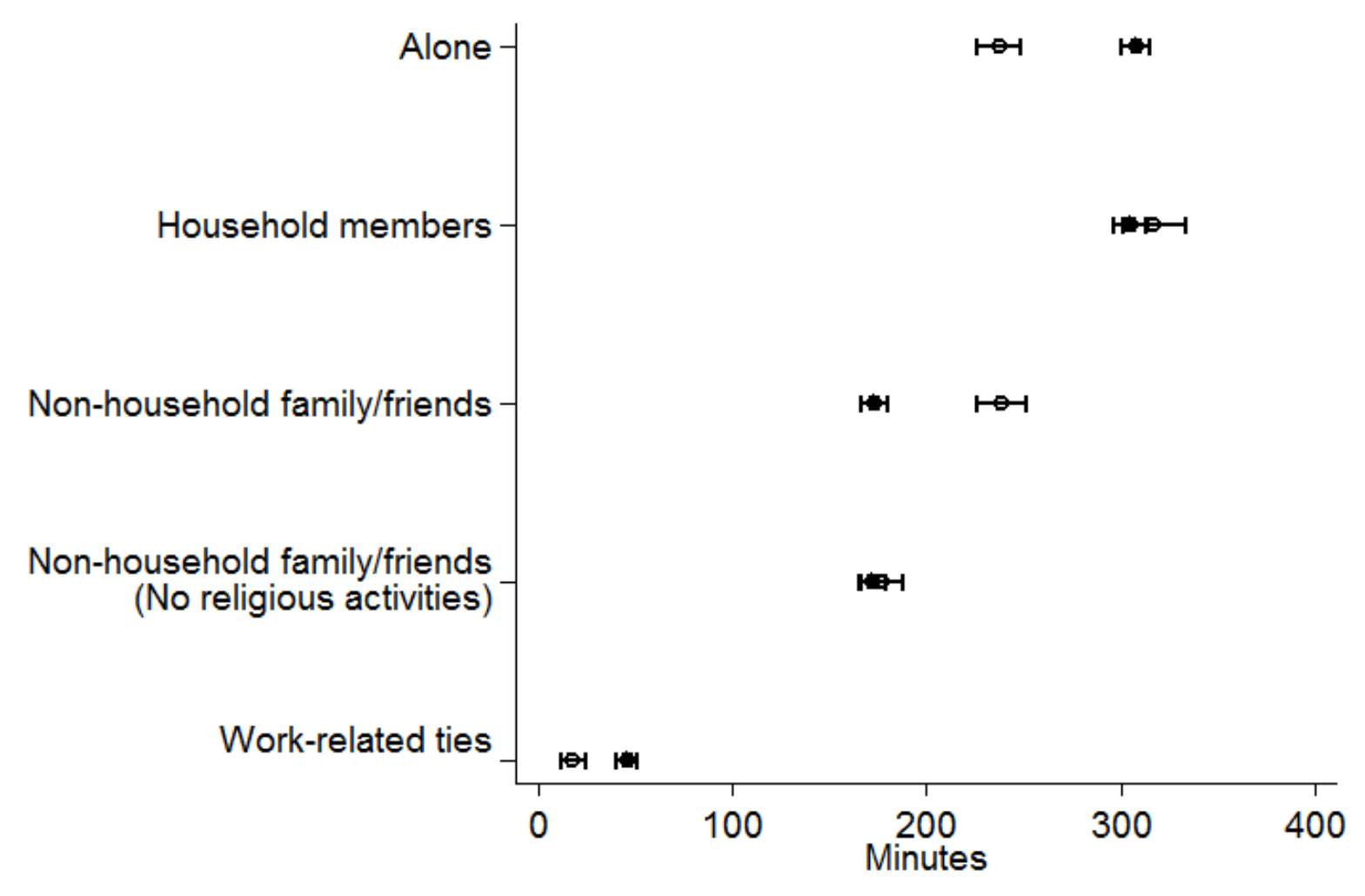

- Non-churchgoer o Churchgoer

Figure 2: Predicted minutes spent with different types of social ties. The predicted minutes and their 95 percent confidence intervals were computed from negative binomial regressions that predict the minutes spent with different types of social ties. The regression models adjust for all individual-level covariates discussed in the paper. Household members may also be present during the time spent with "Non-household family/Friends." The full regression results can be found in the online supplement.

gory is the activity during which nobody else is present. Compared to the activity done alone, people experience more positive feelings during the activities they share with family members and friends. In particular, people experience the highest level of affective well-being when they are with non-household family members and friends. Not all types of company, however, are emotionally rewarding. People find the time on Sunday they share with coworkers or other work-related ties less pleasant than the time they spend alone. As I will show shortly, this is largely because many of the activities shared with coworkers are paid work, which have a low $\mathrm{P}_{a}$-index with or without the presence of other people.

In short, model 2 confirms that, on average, people experience more positive affect during the activities that they share with family members and friends than during the activities done alone. The comparison between models 1 and 2 indicates that adjusting for who are present during a given activity attenuates the coeffi- 
Table 1: Multilevel logistic regressions of the $\mathrm{P}_{a}$-index on religious service attendance and other covariates.

\begin{tabular}{|c|c|c|c|c|c|c|}
\hline & (1) & (2) & (3) & (4) & (5) & (6) \\
\hline Religious service attendance & $\begin{array}{c}0.656^{\dagger} \\
(0.072)\end{array}$ & $\begin{array}{c}0.574^{\dagger} \\
(0.073)\end{array}$ & $\begin{array}{c}0.397^{\dagger} \\
(0.075)\end{array}$ & $\begin{array}{r}0.417^{\dagger} \\
(0.078)\end{array}$ & $\begin{array}{r}0.413^{\dagger} \\
(0.083)\end{array}$ & $\begin{array}{c}0.459^{\dagger} \\
(0.102)\end{array}$ \\
\hline \multicolumn{7}{|l|}{ With whom } \\
\hline Household members & & $\begin{array}{r}0.489^{\dagger} \\
(0.055)\end{array}$ & $\begin{array}{r}0.295^{\dagger} \\
(0.057)\end{array}$ & $\begin{array}{r}0.326^{\dagger} \\
(0.060)\end{array}$ & $\begin{array}{r}0.221^{\dagger} \\
(0.066)\end{array}$ & $\begin{array}{r}0.307^{\dagger} \\
(0.063)\end{array}$ \\
\hline Non-household family/friends & & $\begin{array}{r}1.074^{\dagger} \\
(0.064)\end{array}$ & $\begin{array}{r}0.681^{\dagger} \\
(0.067)\end{array}$ & $\begin{array}{r}0.727^{\dagger} \\
(0.072)\end{array}$ & $\begin{array}{r}0.674^{\dagger} \\
(0.076)\end{array}$ & $\begin{array}{r}0.713^{\dagger} \\
(0.076)\end{array}$ \\
\hline Work-related & & $\begin{array}{r}-0.761^{\dagger} \\
(0.151)\end{array}$ & $\begin{array}{r}-0.438^{\dagger} \\
(0.154)\end{array}$ & $\begin{array}{r}-0.552^{\dagger} \\
(0.205)\end{array}$ & $\begin{array}{c}-0.252 \\
(0.572)\end{array}$ & $\begin{array}{r}-0.352^{*} \\
(0.160)\end{array}$ \\
\hline Average $\mathrm{P}_{a}$-index of the activity & & & $\begin{array}{r}6.576^{\dagger} \\
(0.298)\end{array}$ & $\begin{array}{r}4.506^{\dagger} \\
(0.756)\end{array}$ & $\begin{array}{r}6.762^{\dagger} \\
(0.347)\end{array}$ & $\begin{array}{r}6.583^{\dagger} \\
(0.298)\end{array}$ \\
\hline $\begin{array}{l}\text { Household members } \\
\quad \text { x Religious attendance }\end{array}$ & & & & & & $\begin{array}{r}0.701^{\dagger} \\
(0.105)\end{array}$ \\
\hline $\begin{array}{l}\text { Non-household family/friends } \\
\text { x Religious attendance }\end{array}$ & & & & & & $\begin{array}{r}1.036^{\dagger} \\
(0.125)\end{array}$ \\
\hline $\begin{array}{l}\text { Work-related } \\
\text { x Religious attendance }\end{array}$ & & & & & & $\begin{array}{r}-0.963 \\
(0.567)\end{array}$ \\
\hline Individual-level covariates & Yes & Yes & Yes & Yes & Yes & Yes \\
\hline Harmonized activity fixed-effect & No & No & No & Yes & No & No \\
\hline Constant & $\begin{array}{r}-1.293^{\dagger} \\
(0.460)\end{array}$ & $\begin{array}{r}-1.713^{\dagger} \\
(0.468)\end{array}$ & $\begin{array}{r}-5.786^{\dagger} \\
(0.513)\end{array}$ & $\begin{array}{r}-4.424^{\dagger} \\
(0.696)\end{array}$ & $\begin{array}{r}-5.789^{\dagger} \\
(0.591)\end{array}$ & $\begin{array}{r}-5.807^{\dagger} \\
(0.513)\end{array}$ \\
\hline Var(Constant) & $\begin{array}{r}4.329^{\dagger} \\
(0.188)\end{array}$ & $\begin{array}{r}4.442^{\dagger} \\
(0.194)\end{array}$ & $\begin{array}{r}4.606^{\dagger} \\
(0.203)\end{array}$ & $\begin{array}{r}4.667^{\dagger} \\
(0.207)\end{array}$ & $\begin{array}{c}4.761^{\dagger} \\
(0.240)\end{array}$ & $\begin{array}{r}4.605^{\dagger} \\
(0.203)\end{array}$ \\
\hline N (Activity) & 25,471 & 25,471 & 25,471 & 25,455 & 20,006 & 25,471 \\
\hline N (Individual) & 8,817 & 8,817 & 8,817 & 8,817 & 6,938 & 8,817 \\
\hline
\end{tabular}

Note: Standard errors in parentheses.

$\dagger p<0.01,{ }^{*} p<0.05$

cient of religious service attendance, implying that the well-being gap between churchgoers and non-churchgoers may be partly attributable to their differences in social time. To formally test this possibility, I conducted mediation analysis using the "mediation" package in R (Tingley et al. 2014), in which models 1 and 2 are compared to estimate the proportion of the relationship between religious service attendance and $\mathrm{P}_{a}$-index that can be explained by the types of people who are present during the activity. To simplify the mediation test, I model the mediator (i.e., type of people who are present during the activity) as an interval variable ranging from zero (work-related ties) to three (non-household family/friends). This is a reasonable approximation given the roughly linear relationship between the types of relationship and the $\mathrm{P}_{a}$-index in model 2. The coefficient of religious service 
attendance in the model with the mediator as an interval variable is 0.59 , slightly larger than that in model 2 in Table 1 . The results from the mediation analysis indicate that the type of people present during the activity mediates about 12 percent of the association between religious service attendance and the $\mathrm{P}_{a}$-index with the 95 percent confidence interval ranging from 9 percent to 15 percent. ${ }^{4}$

Still, even after taking the difference in social time into account, much of the gap remains unexplained. To further explore how different ways churchgoers and non-churchgoers spend time is related to the gap in their affective experiences, I examine whether churchgoers allocate more time on Sunday to the activities with higher P-indices in general than non-churchgoers do. I first compute the difference between churchgoers and non-churchgoers in the average amount time they spend on each of all seventy-three harmonized categories of activity that are eligible for the well-being module. Figure 3 presents the differences for all seventy-three categories ordered by the average $\mathrm{P}_{a}$-index of each category among all available respondents (both churchgoers and non-churchgoers) with the category with the highest $\mathrm{P}_{a}$-index on the top. The positive value on the horizontal axis indicates that churchgoers on average spend more time than non-churchgoers on the activity. I flag some categories for which there are notable differences between churchgoers and non-churchgoers. I omit the difference in the amount of time spent for "worship and religious activities," as it dwarfs all the other categories in Figure 3. On average, churchgoers spend 131 minutes more on "worship and religious activities" than non-churchgoers do on Sunday. They also find these activities pleasant, as this category has the eleventh highest average $\mathrm{P}_{a}$-index among the seventy-three activity categories, similar to "general out-of-home leisure" and "hobbies." The complete list of the activity categories with their average $\mathrm{P}_{a}$-index can be found in the online supplement.

Figure 3 shows that in addition to religious activities, churchgoers spend more time than non-churchgoers on the activities that have high average $\mathrm{P}_{a}$-index, including volunteering and meeting with friends. Churchgoers also find the time they travel to attend worship services and volunteer pleasant, maybe because they are accompanied by family and friends or because of the anticipation of attending worship services. In comparison, non-churchgoers spend more time on the activities that are on the lower half of Figure 3. Compared to churchgoers, non-churchgoers spend 42 minutes more watching TV, 45 minutes more on paid work, and about half an hour on various domestic works, including cleaning and laundry. In summary, churchgoers spend more time on the activities that people associate with positive affect than non-churchgoers do, largely because their Sunday is organized around worship services and other social activities before and after the services. Non-churchgoers spend their additional free time on Sunday participating in the activities that are less affectively rewarding, such as TV watching and domestic works.

In model 3 in Table $1, \mathrm{I}$ add the average $\mathrm{P}_{a}$-index for each activity as a predictor to see whether the differences in activity patterns in Figure 3 explain the wellbeing gap between churchgoers and non-churchgoers. As expected, the average $\mathrm{P}_{a}$-index associated with the activity strongly predicts the $\mathrm{P}_{a}$-index that individual respondents report during the activity. Adding the average $\mathrm{P}_{a}$-index further reduces 


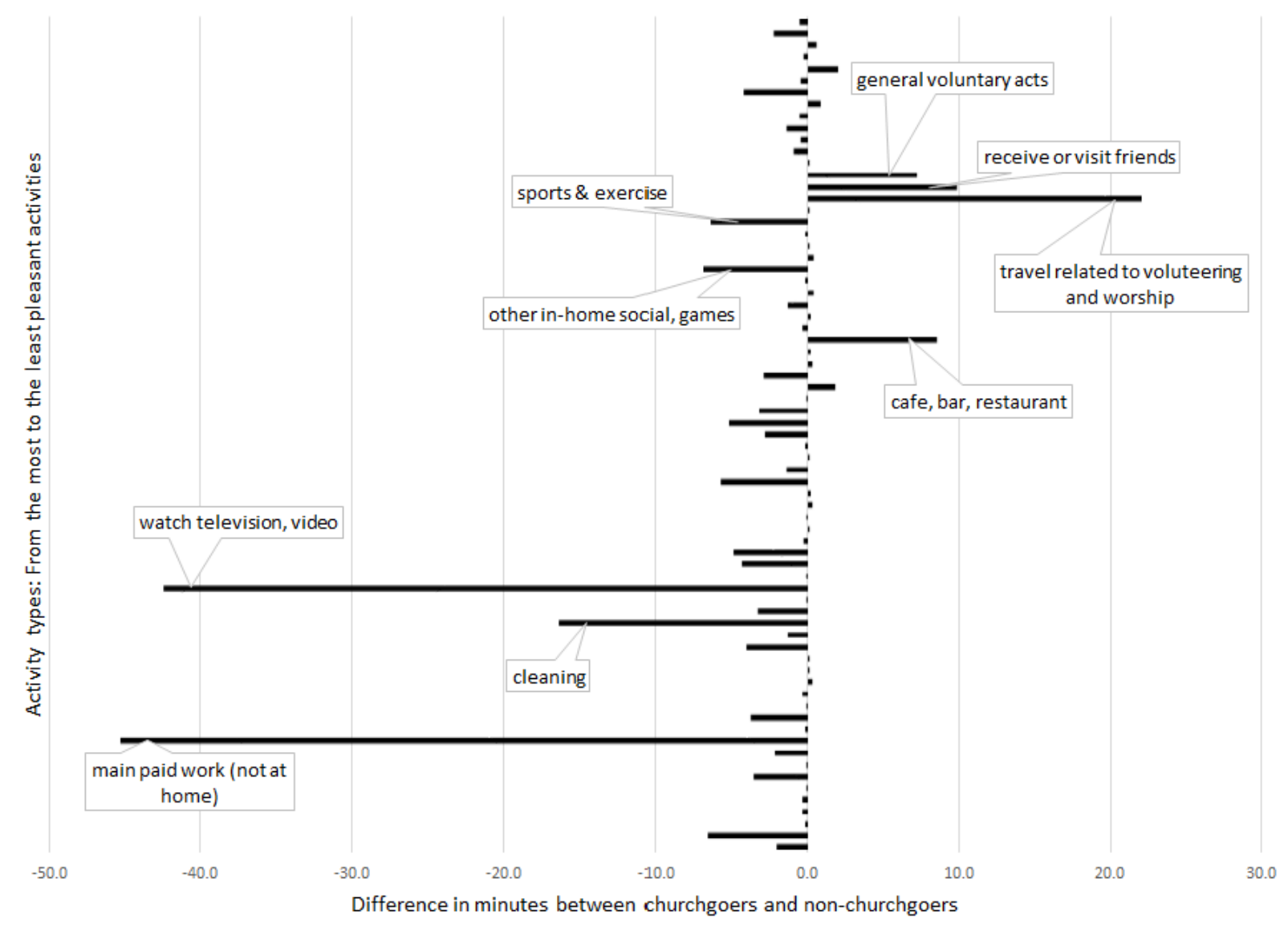

Figure 3: Differences in minutes spent on each of seventy-three activity categories between churchgoers and non-churchgoers on Sunday. Each bar represents the simple difference in average minutes spent by churchgoers and non-churchgoers for each activity category (i.e., average minute by non-churchgoers subtracted from average minute by churchgoers). The categories are sorted from the ones with the highest average $\mathrm{P}_{a}$-index at the top to those with the lowest at the bottom. The difference for "worship and religious activities" is omitted.

the well-being gap between churchgoers and non-churchgoers. A formal mediation test that compares models 2 and 3 reveals that the average $\mathrm{P}_{a}$-index associated with the activity mediates about 32 percent of the remaining association between religious service attendance and affective well-being, with the 95 percent confidence interval being between 26 percent and 41 percent. In sum, a little more than 40 percent of the well-being gap between churchgoers and non-churchgoers can be explained by how much time they spend on the activities they share with family and friends and on the activities that people generally find pleasant.

Even in model 3, however, churchgoers still have a higher $\mathrm{P}_{a}$-index than nonchurchgoers do. In fact, the well-being gap remains about the same even after adding a set of dummy variables for all seventy-three harmonized activities and thus removing the remaining differences in the $\mathrm{P}_{a}$-index due to the differences in the kinds of activities churchgoers and non-churchgoers participate in (model 
4 in Table 1). In other words, a large part (about 60 percent) of the difference in the $\mathrm{P}_{a}$-index between churchgoers and non-churchgoers cannot be explained by what they actually do. The results are similar when we restrict the analyses to the respondents who report no paid work on Sunday, except that the gap in affective well-being between the activities done alone and those done with work-related ties is smaller and insignificant (model 5 in Table 1).

One possible explanation of this remaining gap is that churchgoers draw more intense pleasure from the time they spend with family members and friends who share their own religious faiths (H2). I explore this possibility by adding the interaction terms between the types of people who are present during the activity and religious service attendance (model 6 in Table 1). To facilitate the interpretation, Figure 4 shows the predicted $\mathrm{P}_{a}$-indices separately for churchgoers and non-churchgoers with their 95 percent confidence intervals.

Contrary to what $\mathrm{H} 2$ predicts, the difference in the $\mathrm{P}_{a}$-index between churchgoers and non-churchgoers is not particularly large during social time. In fact, the gap is largest during the activities they do alone and smallest when non-household family members and friends are present, i.e., during the social time people tend to enjoy most. In other words, churchgoers do not seem to draw particularly intense pleasure from social activities they share with family members and friends compared to non-churchgoers.

In summary, the difference in how churchgoers and non-churchgoers allocate their time does explain a significant part of the gap in affective well-being they experience on Sunday. Compared to non-churchgoers, churchgoers spend more time on Sunday socially with friends and family members, especially those outside their households, participating in the activities people generally find more pleasant. However, a large portion of the gap in their affective experiences on Sunday cannot be explained by how they allocate their time among different activities, hinting that the difference may have partly to do with how people feel during the same or a similar activity rather than what activities they do. I return to this issue in the discussion section.

\section{Affective Well-Being during Other Days of the Week}

Thus far, all of the findings are based on the Sunday ATUS data. In this section, I turn to the Gallup data to see whether churchgoers experience a higher level of affective well-being than non-churchgoers during the rest of week. I regress the affective balance score on the frequency of religious service attendance, the day of the week for which respondents report their affective experiences, and the interactions between them. I adjust for the same set of individual-level covariates as the analyses of the ATUS data. Using the results (available in the online supplement), I compute the predicted affective balance scores for each day of the week at different levels of attendance and display them in Figure 5.

In Figure 5, the affective balance score is significantly higher in weekends than in weekdays at all levels of religious service attendance. Regardless of their religious involvement, people experience more positive affective balances in weekends than in weekdays. More relevant to this study, regular churchgoers report a higher level 


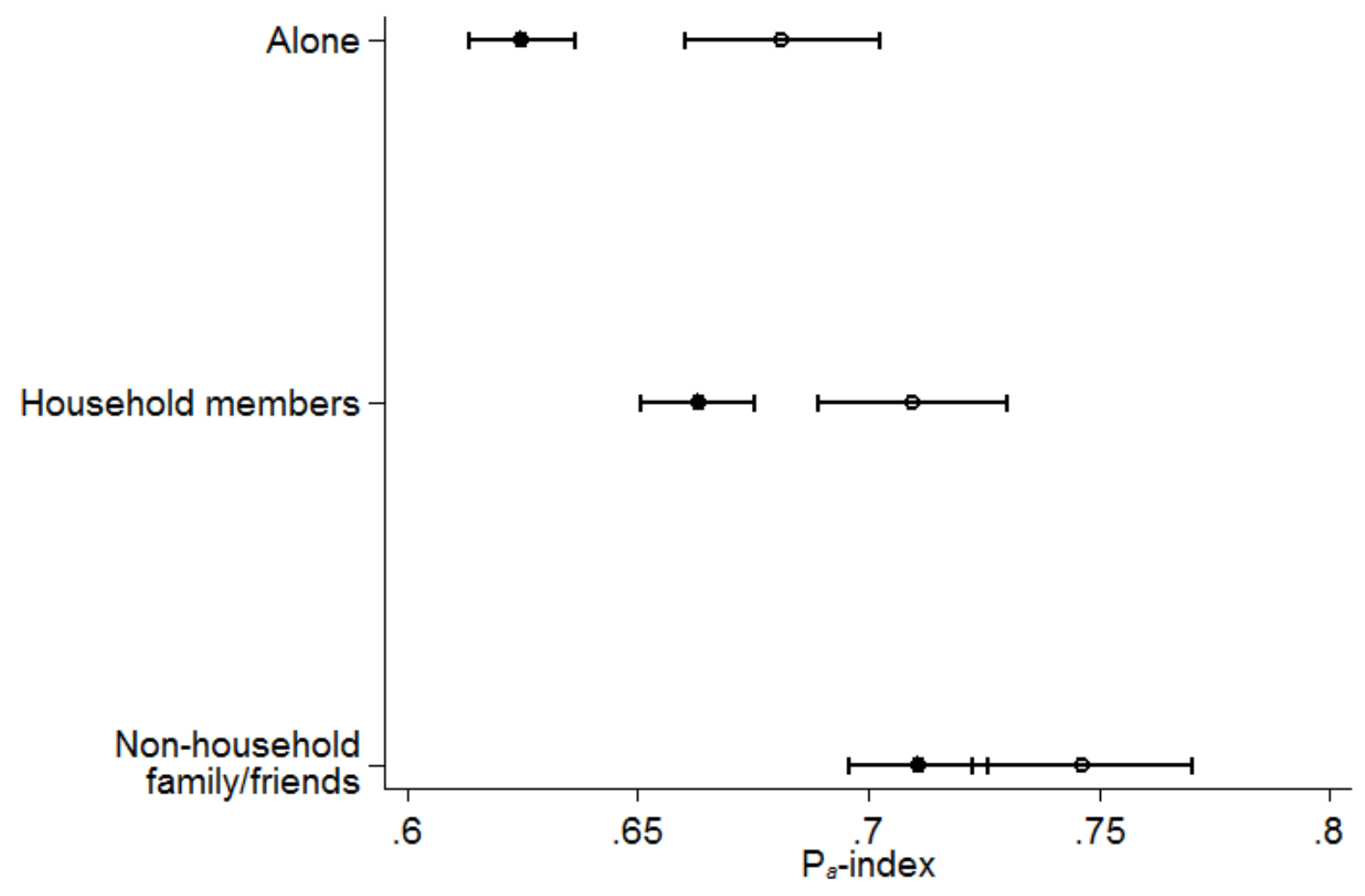

- Non-churchgoer o Churchgoer

Figure 4: Predicted $\mathrm{P}_{i}$-index scores during the time spent with different types of social ties for churchgoers and non-churchgoers. The $\mathrm{P}_{a}$-index scores and their 95 percent confidence intervals were computed from a multilevel logistic regression of the $\mathrm{P}_{a}$-index that includes the interaction terms between religious service attendance and the types of social ties that were present during the activity (see model 6 in Table 1). "Workrelated ties" is omitted to make the other results more interpretable. There is no significant difference in the $\mathrm{P}_{a}$-index between churchgoers and non-churchgoers when they are with "work-related ties."

of affective well-being than non-regular churchgoers or non-churchgoers during any day of the week. There are some subtle differences between churchgoers and non-churchgoers in their day-of-week patterns of affective well-being. Although most Americans feel happier on both Saturday and Sunday than on weekdays, affective well-being peaks on Sunday for weekly churchgoers, whereas for nonchurchgoers who never attend religious services, it peaks on Saturday. As a result, the gap between churchgoers and non-churchgoers is larger on Sunday than on Saturday by about 20 percent. Affective well-being may peak on Saturday rather than on Sunday for non-churchgoers because they spend more time socially on fun activities on Saturday and save Sunday for resting and taking care of chores at home. They may also feel less relaxed on Sunday than on Saturday in anticipation of the beginning of a new workweek, although the same would apply to churchgoers. 


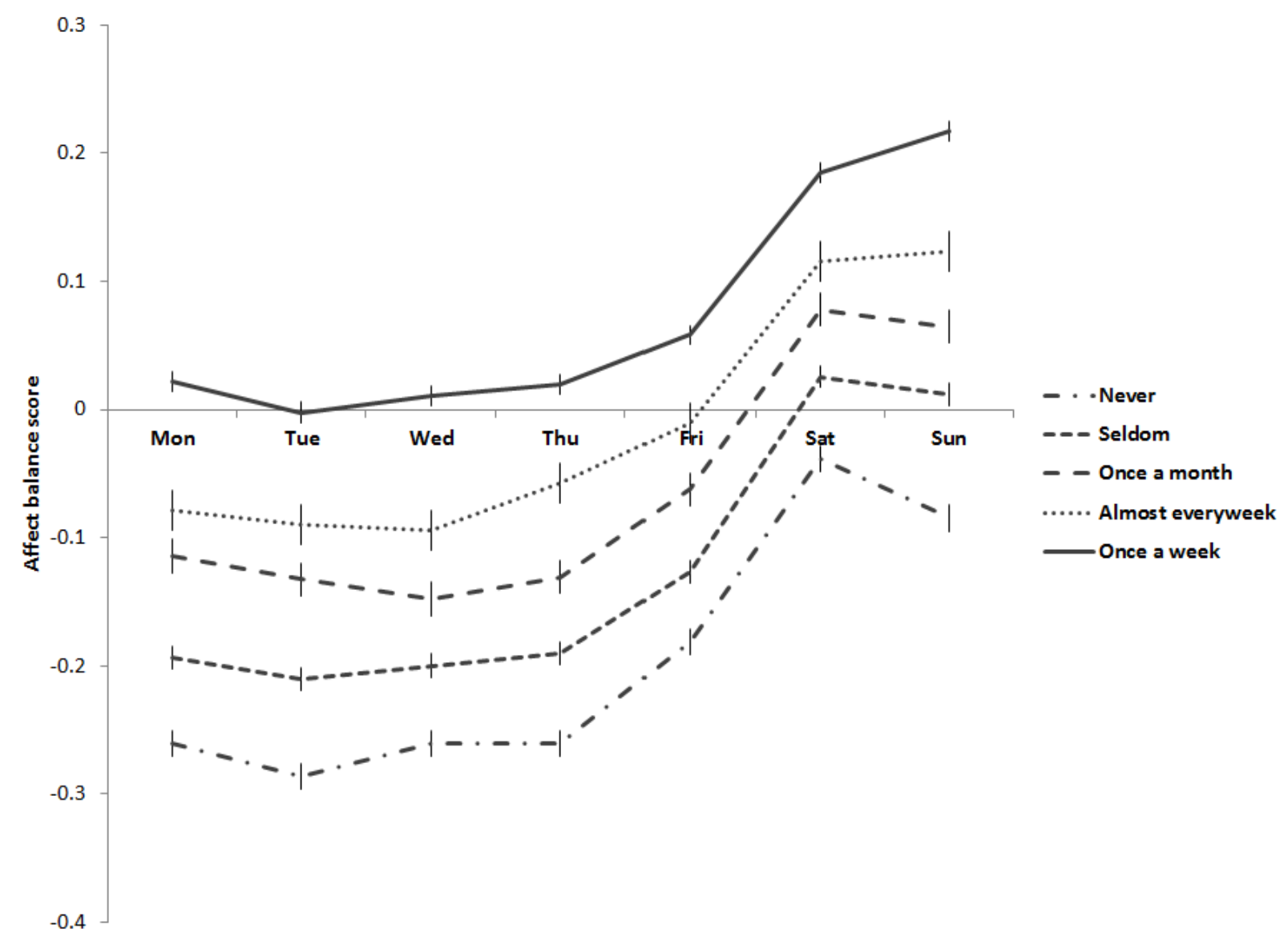

Figure 5: Predicted affective balance score by the day of week for different levels of religious service attendance in the Gallup Daily Poll data. The affective balance scores and their 95 percent confidence intervals were computed from an OLS regression model that includes the interaction terms between the day of the week and the frequency of religious service attendance. The full regression results can be found in the online supplement.

Whatever the source of these differences is, however, churchgoers still have a higher level of affective well-being even on Saturday. Moreover, the gap between churchgoers and non-churchgoers on weekdays is almost as large as that on Sunday. In short, the gap in affective well-being between churchgoers and non-churchgoers is not limited to Sunday; it can be found in all seven days of the week.

\section{Discussion}

This study aimed to examine differences in daily affective experiences of religious and non-religious individuals. By focusing on daily experiences of positive and negative affect of churchgoers and non-churchgoers during specific activities, this study demonstrates that churchgoers not only evaluate their life in a more positive light than non-churchgoers do but also enjoy more positive affective experiences in 
everyday life. Using the ATUS well-being data, this study provides more direct evidence for the relationship between religious involvement and the affective domain of subjective well-being than previous studies that rely on general assessments of happiness or mental health conditions do.

Moreover, the findings in this study offer new insights on the mechanisms that link religious involvement to affective well-being. I demonstrate that at least a part of the gap in affective experiences on Sunday between churchgoers and nonchurchgoers has to do with how they allocate time to different activities. Churchgoers enjoy more positive feelings on Sunday than non-churchgoers do partly because they spend more time participating in pleasant activities with friends and family members and less time alone doing unpleasant activities. Furthermore, the time that churchgoers spend on and around worship services is responsible for much of the differences in time use between them and non-churchgoers.

This last finding highlights the importance of worship service as a natural focal point around which social activities can be organized, especially with nonhousehold family members and friends. For churchgoers, worship service itself is a kind of institutionalized social time they share with extended family members and friends of the same faith. Because it happens regularly at a designated time, it does not require additional scheduling efforts. Moreover, it makes it easier to coordinate additional social events with non-household family members and friends.

Non-churchgoers surely can spend their time on Sunday equally active with family members and friends by organizing non-religious social activities. However, my findings suggest that, on average, they do not do so. Instead, they spend more time alone doing the activities that are less emotionally rewarding. This could be because they do much of their social activities on Friday or Saturday rather than on Sunday. The weekly patterns of affective well-being in the Gallup data are partly consistent with this possibility. However, it is also plausible that non-churchgoers spend less time socially on Sunday, especially with friends and family members outside their households, because it requires additional efforts to schedule social activities. Even on Sunday, scheduling social events, especially with people outside one's household, could be a hassle, as you need to negotiate multiple calendars and arrange the time and place to meet. Although people do often manage to coordinate social time with non-household members, it is not easy to do so week after week unless they have a regular social event in which their relatives and friends participate.

Even though the differences in time use partly explain the gap in affective well-being between churchgoers and non-churchgoers, more than half of the gap remains unexplained. How do we explain this persistent gap? Although the ATUS does not provide sufficient information to deeply explore social and psychological mechanisms to answer this question, the findings in this study offer some insights.

Psychologists have long argued that a large part of interpersonal variance in subjective well-being can be attributed to each individual's personal disposition. In particular, Diener and Lucas (1999) suggest that extraversion and neuroticism are most closely linked to emotion and affect. One possibility, therefore, is that churchgoers are more likely to be extroverts than non-churchgoers. The evidence about the relationship between religiosity and personality traits, however, seems mixed. 
Studies have found that among the "Big Five" personality traits, religiosity is most closely correlated with "agreeableness" and "conscientiousness." The correlations with other traits, including "extraversion" and "neuroticism," are non-existent or weak at best (Saroglou 2002, 2009; Emmons and Paloutzian 2003). Furthermore, the finding in this study that the gap between churchgoers and non-churchgoers in affective well-being is larger when they are alone than with relatives and friends is inconsistent with the prediction that extroverts derive more pleasure from social interactions (Gray 1981; Magnus et al. 1993).

Instead, my findings seem more supportive of what sociological studies on religion and well-being have long suggested. The deep sense of belonging and attachment, reinforced by social ties that share religious faith, can provide churchgoers with social and psychological resources to cope with challenges in daily life (Ellison 1991; Pargament 1997). Religion's teaching about gratitude can also help churchgoers to find meaning and happiness even during mundane daily activities (Park et al. 2004; Krause 2006). This religion-as-coping-resources view is consistent with the finding that the gap in the P-index between churchgoers and non-churchgoers is the largest during the activities done alone. Religion can also serve as a mechanism that help people manage their feelings and regulate how they express them in given social contexts (Hochschild 1979; Thoits 1989; Simon and Nath 2004). Compared to non-churchgoers, whose P-index swings considerably depending on what activities they participate in and who they are with, churchgoers maintain a relatively stable level of affective well-being throughout the day, the finding that is consistent with this view about religion and emotion management.

In addition to extending our understanding of the link between religion and well-being, this study also demonstrates the utility of time diary data for sociological research on subjective well-being and human emotions. Thoits (1989) points out that we have limited systematic knowledge about how affective experiences are distributed across social groups and positions. Using the ATUS, this study documents the distributions of daily affective experiences along one of the key sociological variables. Hopefully future research will continue to take advantage of time diary data to advance our understanding of the social and cultural dynamics of human well-being and emotions.

\section{Notes}

1 Certain activities (e.g., sleeping) are not eligible for the well-being module and thus excluded from the sampling frame.

2 The following activities are ineligible for this question: sleeping, grooming, and other personal activities (e.g., cuddling, making out, etc.) (Bureau of Labor Statistics, 2011).

3 This includes the time during which household members are also present along with non-household family members or friends.

4 The estimates are based on 100 simulations. Both the "direct effect" and the "mediated effect" are statistically significant at $\mathrm{p}<0.001$. The detailed results are available in the online supplement. 
5 An earlier version of this figure appeared online in Lim (2012). The current version is based on a significantly larger sample size than the previous version. It also combines positive and negative affect into a single composite index.

\section{References}

Baumeister, Roy F., and Mark R. Leary. 1995. "The Need to Belong: Desire for Interpersonal Attachments as a Fundamental Human Motivation." Psychological Bulletin 117:497-529. http://dx.doi.org/10.1037/0033-2909.117.3.497

Brenner, Philip S. 2011. "Exceptional Behavior or Exceptional Identity? Over-reporting of Church Attendance in the US." Public Opinion Quarterly 75:19-41. http://dx. doi .org/ $10.1093 / \mathrm{poq} / \mathrm{nfq} 068$

Bureau of Labor Statistics. 2011. "American Time Use Survey: Well-being Module Questionnaire." Technical report, Bureau of Labor Statistics.

Cohen, Sheldon. 2004. "Social relationships and health." American psychologist 59:8. http: //dx.doi.org/10.1037/0003-066x.59.8.676

Collins, Randal. 2004. Interaction Ritual Chains. Princeton: Princeton University Press. http://dx.doi.org/10.1515/9781400851744

Csikszentmihalyi, Mihaly, and Reed Larson. 2014. "Validity and reliability of the experiencesampling method." In Flow and the Foundations of Positive Psychology, edited by Mihaly Csikszentmihalyi, pp. 35-54. The Netherlands: Springer. http://dx.doi .org/10.1007/ 978-94-017-9088-8_3

Diener, Ed, Daniel Kahneman, William Tov, and Raksha Arora. 2010. "Income's Association with Judgments of Life Versus Feeling." In International Differences in Well- Being, edited by E. Diener, J. F. Helliwell, and D. Kahneman, pp. 3-15. New York: Oxford University Press. http://dx.doi.org/10.1093/acprof : oso/9780199732739.003.0001

Diener, Ed, and Richard E. Lucas. 1999. "Personality and Subjective Well-Being." In Wellbeing: Foundations of Hedonic Psychology, edited by D Kahneman, N. Schwart, and E. Diener, pp. 213-229. New York: Russell Sage Foundation Publications.

Ellison, Christopher G. 1991. "Religious Involvement and Subjective Well-being." Journal of Health and Social Behavior 32:80-99. http://dx . doi .org/10.2307/2136801

Ellison, Christopher G., Amy M. Burdette, and Terrence D. Hill. 2009. "Blessed assurance: Religion, anxiety, and tranquility among US adults." Social Science Research 38:656-667. http://dx.doi.org/10.1016/j.ssresearch.2009.02.002

Ellison, Christopher G., and Daisy Fan. 2008. "Daily Spiritual Experiences and Psychological Well-being among US Adults." Social Indicators Research 88:247-271. http://dx.doi . org/10.1007/s11205-007-9187-2

Ellison, Christopher G., David A. Gay, and Thomas A. Glass. 1989. "Does religious commitment contribute to individual life satisfaction?" Social Forces 68:100-123. http: //dx.doi.org/10.1093/sf/68.1.100

Ellison, Christopher G., and Jinwoo Lee. 2010. "Spiritual Struggles and Psychological Distress: Is There a Dark Side of Religion." Social Indicators Research 98:501-517. http: //dx.doi.org/10.1007/s11205-009-9553-3

Ellison, Christopher G. and Jeffrey S. Levin. 1998. "The religion-health connection: Evidence, theory, and future directions." Health Education \& Behavior 25:700-720. http://dx . doi . org/10.1177/109019819802500603 
Emmons, Robert A., and Raymond F. Paloutzian. 2003. "The psychology of religion." Annual review of psychology 54:377-402. http://dx.doi.org/10.1146/annurev.psych.54. 101601.145024

Gallup, Inc. 2009. "Gallup-Healthways Well-Being Index: Methodology report for indexes." http://wbi.meyouhealth.com/files/GallupHealthwaysWBI-Methodology ·pdf .

Gray, Jeffrey A. 1981. "A critique of Eysenck's theory of personality." In A model for personality, edited by H. J. Eysenck, pp. 246-276. New York: Springer-Verlag. http: //dx.doi.org/10.1007/978-3-642-67783-0_8

Hadaway, C. Kirk, Penny Long Marler, and Mark Chaves. 1993. "What the Polls Don't Show: A Closer Look at U.S. Church Attendance." American Sociological Review 58:741-52. http://dx.doi.org/10.2307/2095948

Hochschild, Arlie R. 1979. "Emotion, Work, Feeling Rules, and Social Structure." American Journal of Sociology 85:551-575. http://dx. doi.org/10.1086/227049

Kahneman, Daniel. 2011. Thinking, Fast and Slow. New York: Farrar, Straus and Giroux.

Kahneman, Daniel, and Alan B. Krueger. 2006. "Developments in the measurement of subjective well-being." The Journal of Economic Perspectives 20:3-24. http://dx . doi . org/10.1257/089533006776526030

Kahneman, Daniel, David A. Schkade, Claude Fischer, Alan B. Krueger, and Amy Krilla. 2010. "The Structure of Well-Being in Two Cities: Life Satisfaction and Experienced Happiness in Columbus, Ohio and Rennes, France." In International Differences in Well-Being, edited by E. Diener, J. F. Helliwell, and D. Kahneman, pp. 16-33. New York: Oxford University Press. http://dx.doi.org/10.1093/acprof : oso/9780199732739.003.0002

Kirkpatrick, Lee A. 1995. "Attachment and religious experience." In Handbook of religious experience: Theory and practice, edited by Jr R. W. Hood, pp. 446-475. Birmingham, AL: Religious Education Press.

Koenig, Harold, Dana King, and Verna B. Carson. 2012. Handbook of religion and health. New York: Oxford university press.

Krause, Neal. 2006. "Gratitude toward God, stress, and health in late life." Research on Aging 28:163-183. http://dx.doi.org/10.1177/0164027505284048

Krause, Neal, and Christopher G. Ellison. 2009. "The Doubting Process: A Longitudinal Study of the Precipitants and Consequences of Religious Doubt in Older Adults." Journal for the Scientific Study of Religion 48:293-312. http://dx .doi .org/10.1111/j.1468-5906. 2009.01448.x

Krause, Neal, and Keith M. Wulff. 2005. "Church-Based Social Ties, a Sense of Belonging in a Congregation, and Physical Health Status." International Journal for the Psychology of Religion 15:73-93. http://dx.doi.org/10.1207/s15327582ijpr1501_6

Krueger, Alan B., Daniel Kahneman, David Schkade, Nobert Schwarz, and Arthur A. Stone. 2009. "National Time Accounting: The Currency of Life." In Measuring the Subjective Well- Being of Nations: National Accounts of Time Use and Well-Being, edited by A. B. Krueger, pp. 9-86. Chicago, IL: University of Chicago Press. http://dx.doi .org/10 . 7208/chicago/9780226454573.003.0002

Lim, Chaeyoon. 2012. "In U.S., Churchgoers Boast Better Mood, Especially on Sunday." http://www.gallup.com/poll/153374/ churchgoers-boast-better-mood-especially-sundays . aspx

Lim, Chaeyoon, and Robert D. Putnam. 2010. "Religion, Social Networks, and Life Satisfaction." American Sociological Review 75:914-933. http://dx.doi.org/10.1177/ 0003122410386686 
Lykken, David. 1999. Happiness: What studies on twins show us about nature, nurture, and the happiness set-point. New York: Golden Books.

Magnus, Keith, Ed Diener, Frank Fujita, and William Pavot. 1993. "Extraversion and neuroticism as predictors of objective life events: a longitudinal analysis." Journal of personality and social psychology 65:1046-1053. http://dx.doi.org/10.1037/0022-3514.65.5. 1046

McCullough, Michael E., and David B. Larson. 1999. "Religion and depression: a review of the literature." Twin Research 2:126-136. http://dx.doi.org/10.1375/ 136905299320565997

McFadden, Susan H., and Jeffrey S. Levin. 1996. "Religion, emotions, and health." In Handbook of Emotion, Adult Development, and Aging, pp. 349-365. San Diego, CA: Academic Press. http://dx.doi .org/10.1016/B978-012464995-8/50020-0

Pargament, Kenneth. 1997. The psychology of religion and coping: Theory, research, and practice. New York, NY: Guilford Press.

Park, Nansook, Christopher Peterson, and Martin E. P. Seligman. 2004. "Strengths of Character and Well-Being." Journal of Social and Clinical Psychology 23:603-19. http: //dx.doi.org/10.1521/jscp.23.5.603.50748

Presser, Stanley, and Linda Stinson. 1998. "Data Collection Mode and Social Desirability Bias in Self-reported Religious Attendance." American Sociological Review 63:137-45. http://dx.doi.org/10.2307/2657486

Reiss, Harry T. 2001. "Relationship experiences and emotional well-being." In Emotion, social relationships, and health, edited by C. D. Ryff and B. H. Singer, pp. 57-86. New York, NY: Oxford University Press. http://dx.doi.org/10.1093/acprof : oso/9780195145410. 003.0003

Reiss, Harry T., Shelly L Gable, and Michael R Maniaci. 2014. "Methods for studying everyday experience in its natural context." In Handbook of Research Methods in Social and Personality Psychology, edited by HT Reis and CM Judd, pp. 373-403. Cambridge University Press.

Robinson, John P., and Geoffrey Godbey. 1999. Time for Life. State College. PA: Pennsylvania State University Press.

Saroglou, Vassilis. 2002. "Religion and the five factors of personality: A meta-analytic review." Personality and individual differences 32:15-25. http://dx . doi .org/10 . 1016/ S0191-8869 (00)00233-6

Saroglou, Vassilis. 2009. "Religiousness as a cultural adaptation of basic traits: A fivefactor model perspective." Personality and social psychology review 14:108-125. http: //dx.doi.org/10.1177/1088868309352322

Simon, Robin W., and Leda E. Nath. 2004. "Gender and Emotion in the United States: Do Men and Women Differ in Self-Reports of Feelings and Expressive Behavior?" American journal of sociology 109:1137-1176. http://dx.doi.org/10.1086/382111

Sternthal, Michelle J., David R. Williams, Marc A. Musick, and Anna C. Buck. 2010. "Depression, Anxiety, and Religious Life A Search for Mediators." Journal of Health and Social Behavior 51:343-359. http://dx.doi.org/10.1177/0022146510378237

Thoits, Peggy A. 1989. "The sociology of emotions." Annual review of sociology 15:317-342. http://dx.doi.org/10.1146/annurev.so.15.080189.001533

Tingley, Dustin, Teppei Yamamoto, Kentaro Hirose, Luke Keele, and Kosuke Imai. 2014. "mediation: R Package for Causal Mediation Analysis." Journal of Statistical Software 59:1-38. http://dx.doi.org/10.18637/jss.v059.i05 
Turner, Jonathan H., and Jan E Stets. 2006. "Sociological theories of human emotions." Annual Review of Sociology pp. 25-52.

Waldinger, Robert J., and Marc S Schulz. 2010. "What's love got to do with it? Social functioning, perceived health, and daily happiness in married octogenarians." Psychology and aging 25:422.

Winship, Christopher. 2009. "Time and Scheduling." In Oxford Handbook of Analytical Sociology, edited by P. Hedström and P. Bearman, pp. 499-520. Oxford, UK: Oxford University Press.

Witter, Robert A.,William A. Stock, Morris A. Okun, and Marilyn J. Haring. 1985. "Religion and Subjective Well-Being in Adulthood: A Quantitative Synthesis." Review of Religious Research 26:332-42. http://dx.doi.org/10.2307/3511048

Young, Cristobal, and Chaeyoon Lim. 2014. "Time as a Network Good: Evidence from Unemployment and the Standard Workweek." Sociological Science 1:10-27. http: //dx.doi.org/10.15195/v1.a2

Chaeyoon Lim: Department of Sociology, University of Wisconsin-Madison.

E-mail: chaeyoon.lim@wisc.edu. 